\title{
Purification and properties of baboon chorionic gonadotrophin
}

\author{
C. S. Bambra \\ Institute of Primate Research, National Museums of Kenya, P.O. Box 24481, Karen, Nairobi, \\ Kenya
}

\begin{abstract}
Summary. Baboon CG from the urine and placenta (Days 33-45 of gestation) was purified by ammonium acetate/alcohol extraction followed by ionic exchange, gel filtration and affinity chromatography. The CG activity was monitored using a doubleantibody radioimmunoassay utilizing anti-baboon $\mathrm{CG}$ and hCG both as the labelled ligand and standard. Biological activity was measured by the rat luteal cell radioreceptor assay. The purified preparation exhibited heterogeneity in terms of its behaviour during ionic exchange chromatography and isoelectric focussing. Like hCG, baboon CG was made up of two non-covalently linked subunits: the Stokes' radii were $36 \cdot 5,29 \cdot 0$ and $22 \cdot 0 \times 10^{-10} \mathrm{~m}$ for native $\mathrm{CG}$, the beta subunit and the alpha subunit. The material focussed between $\mathrm{pH} 4 \cdot 2$ and $5 \cdot 5$. Relative to the second international hCG standard the biological potency of the purified urinary baboon CG was 4058 i.u. whilst the immunological activity was 4364 i.u. It is concluded that baboon and human $\mathrm{CG}$ are very similar with respect to their physicochemical properties and that baboon $\mathrm{CG}$ can be purified by the methods that have been developed for hCG.
\end{abstract}

\section{Introduction}

Understanding of the mechanisms controlling early human pregnancy has many practical applications such as in developing new methods of fertility control. For such studies nonhuman primates would be the animal models of choice since the corpus luteum of the cycle in all primates is maintained as the corpus luteum of pregnancy by a luteotrophic stimulus, possibly elicited by chorionic gonadotrophin (Short, 1969; Heap \& Perry, 1974; Ottobre \& Stouffer, 1984). Chorionic gonadotrophin (CG) is believed to be present in the urine, blood and placenta of all pregnant primates (see Tullner, 1974; Hearn, 1980). It has been shown that immunization of baboons and humans with $\beta$-hCG disrupts implantation which supports the feasibility of using this approach for developing a fertility control vaccine (Talwar et al., 1976; Stevens, 1980). Although hCG has been purified and characterized (Bahl, 1969; Morgan \& Canfield, 1971) little information is available on the properties of baboon chorionic gonadotrophin and its relation to hCG. Baboon CG exhibits heterogeneous behaviour in chromatographic studies (Ochieng, 1982).

Even though limited Phase 1 clinical trials involving immunization of women with carboxyl portions of $\beta$-hCG are underway, detailed studies on the toxicology and mechanism of action cannot be carried out for ethical reasons. Such studies therefore need to be done in a suitable animal model, preferably a nonhuman primate. The present paper describes the steps undertaken to purify baboon $\mathrm{CG}$ and to compare its physicochemical properties with hCG.

\section{Materials and Methods}

For use in the bioassay, hCG (Primogonyl) and PMSG (Anteron) were purchased from Schering AG (Berlin, West Germany). Blue dextran, cytochrome $C$, ferritin, bovine serum albumin, ovalbumin and carbonic anhydrase were purchased from Sigma Chemical Co. (St Louis, MO, U.S.A.). Sephadex G100, Concanavalin A and Sepharose 4B 
were products of Pharmacia Fine Chemicals (Uppsala, Sweden). For iodination purified hCG (K881) with a potency of 10000 i.u./mg was kindly provided by Professor R. Ryan (Department of Cell Biology, Mayo Clinic, Rochester, Minnesota, U.S.A.). Partly purified urinary baboon CG was provided by Professor V. Stevens (Department of Obstetrics and Gynecology, Ohio State University, Columbus, Ohio, U.S.A.).

Crude extracts. Partly purified hCG (Organon Ltd, Oss, The Netherlands) was processed to purity by Sephadex G100 gel filtration and DEAE-cellulose chromatography following procedures described by Keutmann et al. (1983).

Extracts of 29 baboon (33-45 days of gestation) and 5 human term placentae were prepared by homogenization in $300 \mathrm{~mm}$-potassium chloride and lyophilization of the supernatant. The gonadotrophin activity was extracted in $40 \%$ ethanol containing $1 \mathrm{M}$-ammonium acetate $(\mathrm{pH} 8.5), 1 \%$ soybean trypsin inhibitor and $1 \%$ phenylmethylsulphonyl fluoride. The extraction was carried out overnight at $4 . \mathrm{C}$ and the supernatant collected after centrifugation at $500 \mathrm{~g}$. Ethanol concentration was adjusted at $90 \%$ with gentle stirring. The precipitate was collected after centrifugation at $500 \mathrm{~g}$ and washed with $90 \%$ ethanol, $100 \%$ ethanol and acetone. The dried acetone powder was used in subsequent studies.

Baboon urine was collected twice daily, from 29 female baboons between Days 18 and 33 of pregnancy, into an ice-cold vessel containing $30 \mathrm{mg}$ soybean trypsin inhibitor, $1 \mathrm{~g}$ sodium azide, $3.8 \mathrm{~g}$ EGTA and $100 \mathrm{ml} 0.5 \mathrm{M}$-sodium phosphate buffer ( $\mathrm{pH} 7 \cdot 0$ ). Daily pooled urine collections were stored at $-20^{\circ} \mathrm{C}$. At the end of the collection urine was filtered and precipitated using a sodium benzoate/acetic acid procedure. Sodium benzoate $(25 \mathrm{~g} / 1)$ was dissolved with the urine and its $\mathrm{pH}$ adjusted to 4.5 with acetic acid. The precipitate formed was collected by filtration through a Buchner funnel and the benzoic acid was dissolved with cold acetone $\left(-20^{\circ} \mathrm{C}\right)$. The precipitate formed overnight was collected by filtration, dried with acetone, dissolved in $1 \mathrm{M}$-ammonium bicarbonate and lyophilized. The gonadotrophic activity was extracted by the ammonium acetate/alcohol procedures as described for the placentae. This extract was used in the following studies.

Assays. The baboon extracts were monitored for immunoactive CG activity using a double-antibody procedure described by Bambra et al. (1984). This assay used a rabbit antiserum against baboon CG (2001-102782) kindly provided by Professor V. Stevens (Ohio State University) and was used at a final dilution of 1:3000. The radiolabelled ligand was prepared at the Institute of Primate Research utilizing the K881 hCG preparation which was also used as the standard. The sensitivity of the assay $(\mathrm{B} / \mathrm{Bo}=90 \%)$ was $0 \cdot 2 \mathrm{ng} /$ tube. Inter- and intra-assay coefficients of variation were $11 \%$ and $6.6 \%$ respectively. Protease inhibitor (soybean trypsin inhibitor) was incorporated in all assay buffers.

Competitive binding to rat luteal cell membrane receptors for hCG was measured by the method of Lee \& Ryan (1975). The hCG used for radioiodination and as a standard was the K881 preparation as described above. The sensitivity of the assay was $0.5 \mathrm{ng} /$ tube and the intra-assay $\mathrm{CV}$ was $10.5 \%$. Soybean trypsin inhibitor was incorporated in all assay buffers

Statistics. Linearity of standard points was determined by regression analysis and tested for lack of fit by ANOVA (Snedecor \& Cochran, 1980). Standard lines were compared for lack of parallelism by the tests of heterogeneity of regression using the method of Snedecor \& Cochran (1980).

DEAE-cellulose chromatography. A $2.6 \times 24 \mathrm{~cm}$ column of DEAE-52 cellulose (Whatman, Bristol, U.K.) was equilibrated with $50 \mathrm{~mm}$-ammonium bicarbonate $(\mathrm{pH} 8 \cdot 6)$. Baboon urinary acetone extract $(1.7 \mathrm{~g} / 10 \mathrm{ml}$ ammonium bicarbonate) was then applied in two separate runs. Elution was begun with the equilibrating buffer followed by a linear gradient of 50-250 mM-ammonium bicarbonate over an $8 \mathrm{~h}$ period. Chromatography was performed at $4^{\circ} \mathrm{C}$ and $5-\mathrm{ml}$ fractions were collected. Placental acetone extract $(5 \mathrm{~g} / 10 \mathrm{ml}$ ammonium bicarbonate) was also chromatographed under identical conditions in two runs. Column eluates were monitored for optical density at $280 \mathrm{~nm}$ and $\mathrm{CG}$ activity using the radioimmunoassay as described above. Fractions containing CG activity were pooled, dialysed and lyophilized.

For comparative purposes, urinary hCG, human placental extract, and baboon urinary and placental extracts were chromatographed separately on a $2.6 \times 26 \mathrm{~cm}$ column of DEAE- 52 cellulose equilibrated with $50 \mathrm{mM}-$ ammonium bicarbonate under identical conditions as described above.

Sephadex G100 gel filtration. Sephadex G100 column $(2 \cdot 6 \times 82 \mathrm{~cm})$ chromatography was performed by upward flow in $100 \mathrm{~mm}$-ammonium bicarbonate solution at $4^{\circ} \mathrm{C}$ as previously described (Ryan, 1969). Eluate samples (5 ml) were collected in a refrigerated fraction collector. The same column was used for all samples obtained from the DEAE-52 step and was repeatedly standardized by using markers of known molecular dimensions (Ryan, 1969). Ferritin, bovine serum albumin, ovalbumin, carbonic anhydrase, cytochrome C (Sigma) and radioiodinated urinary native hCG were used. Column eluates were monitored for optical density at $280 \mathrm{~nm}$ and CG activity using the radioimmunoassay described above. Fractions containing CG activity were pooled, dialysed and lyophilized.

Concanavalin $A$ (ConA) chromatography. Concanavalin A ( $3 \mathrm{ml}$ packed volume) was washed and equilibrated with $40 \mathrm{~mm}$-Tris (pH 7.4). Urinary baboon CG from the gel filtration step (25 mg) was added to Con $A$ in a sealed tube and mixed overnight at $4^{\circ} \mathrm{C}$. The mixture was then poured into a $1.6 \times 4 \mathrm{~cm}$ column and the void volume collected. The column was then washed with $100 \mathrm{~mm}$-sodium chloride in $40 \mathrm{~mm}$-Tris until no protein eluted as deter-

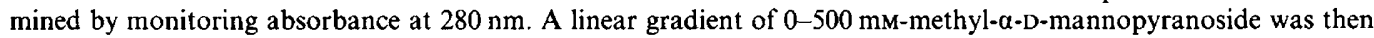
applied over a 1 -h period. Fractions of $1 \mathrm{ml}$ were collected and assayed for $\mathrm{CG}$ activity using the radioimmunoassay procedures outlined above. The procedure was repeated with $13.7 \mathrm{mg}$ baboon placental extract from the gel filtration step, $14 \mathrm{mg}$ urinary hCG extract and $10 \mathrm{mg}$ human placental extract. Pooled peaks were extensively dialysed against $50 \mathrm{~mm}$-ammonium bicarbonate and lyophilized. 
Affinity chromatography using rabbit anti-baboon $C G$ on Sepharose $4 B$. Rabbit anti-baboon CG (5 mg) was coupled to affinity gel 10-Sepharose 4B according to the procedure of Levy \& Eveleigh (1978). The gel was washed with high salt buffers and finally with $40 \mathrm{~mm}$-Tris (pH 7.4). Urinary baboon CG extract from the Con A step (19.3 mg) was added to the gel in $40 \mathrm{mM}$-Tris and the mixture was gently rocked for $7 \mathrm{~h}$ at room temperature. The gel was poured into a 5-ml syringe with glass wool at the bottom. The column was washed with 3 volumes of $40 \mathrm{~mm}$-sodium phosphate buffer $\mathrm{pH} 7.0$ and $1-\mathrm{ml}$ fractions were collected. The column was clamped and $2 \mathrm{ml} 1 \mathrm{M}$-propionic acid containing $10 \%$ dioxane were added. After $60 \mathrm{~min}$ the column was eluted with $3 \mathrm{ml}$ of the same buffer followed by (a) $3 \mathrm{ml} 1 \mathrm{M}$-acetic acid, $1 \mathrm{M}$-guanidine and $100 \mathrm{~mm}$-glycine mixture and (b) $3 \mathrm{ml} 6 \mathrm{M}$-urea. Fractions of $1 \mathrm{ml}$ were collected into tubes containing $1 \mathrm{ml} 10 \mathrm{M}$-ammonium bicarbonate. Tubes eluted with the same buffer were pooled, dialysed extensively against $50 \mathrm{~mm}$-ammonium bicarbonate and lyophilized. These were then assayed using the radioreceptorand radioimmunoassays.

Separation of subunits. A column of DEAE-52 cellulose $(1.6 \times 20 \mathrm{~cm})$ was equilibrated with a buffer containing $3 \mathrm{~mm}$-boric acid and $7 \mathrm{~mm}$-disodium hydrogen phosphate ( $\mathrm{pH} 8.0$ ). Purified urinary baboon CG (10 $\mathrm{mg}$ ) was incubated with $0.4 \mathrm{ml}$ of the above buffer containing $3.6 \mathrm{ml} 11 \mathrm{M}$-urea overnight at room temperature. One volume of the same buffer containing $3 \mathrm{M}$-urea was run through the column and the baboon CG sample applied. The column was washed with a buffer containing $30 \mathrm{~mm}$-boric acid, $70 \mathrm{~mm}$-sodium dihydrogen phosphate and $3 \mathrm{M}$-urea. The column was then eluted with gradients of (a) $0-0.1 \mathrm{M}$-sodium chloride and (b) $0.1-0.5 \mathrm{M}$-sodium chloride in a buffer containing $3 \mathrm{~mm}$-boric acid, $7 \mathrm{~mm}$-disodium hydrogen phosphate and $3 \mathrm{~m}$-urea $(\mathrm{pH}$ 8). Column eluates were monitored for optical density at $280 \mathrm{~nm}$ and CG activity using the radioimmunoassay described above. Pooled peaks were dialysed for 3 days against phosphate borate containing $1 \mathrm{M}$-urea followed by distilled water and lyophilized. They were then rechromatographed on the same Sephadex G100 column used above with $50 \mathrm{~mm}$-ammonium bicarbonate.

Protein determination. Protein levels of pooled peaks were determined by a microprotein determination method using phenol reagent (Sigma Diagnostic Total Protein kit 690-A). This method was used because protein estimates could be carried out on small quantities of the baboon material.

Isoelectric focussing. Isoelectric focussing was performed according to the method of Winter et al. (1977) using ampholyte gradients of $\mathrm{pH} 3 \cdot 5 \cdot 9 \cdot 5$ or $4 \cdot 0.6 \cdot 5$. Proteins focussing at different $\mathrm{pH}$ points were eluted and assayed for baboon CG activity.

Results

\section{Assays}

Initial assaying revealed that both the baboon placenta and urine gave valid radioimmuno- and radioreceptor-assay results. This was shown by the linearity of the standard points and serial dilutions of urine and placenta when analysed by ANOVA. There was no evidence that the serial dilutions of these extracts were not parallel to the hCG standard curves (Fig. 1). Baboon urinary extract had a relative potency of $26.0 \mathrm{i} . \mathrm{u} . / \mathrm{mg}$ whilst that of the placental extract was $0.5 \mathrm{i} . \mathrm{u} . / \mathrm{mg}$ (Table 1).

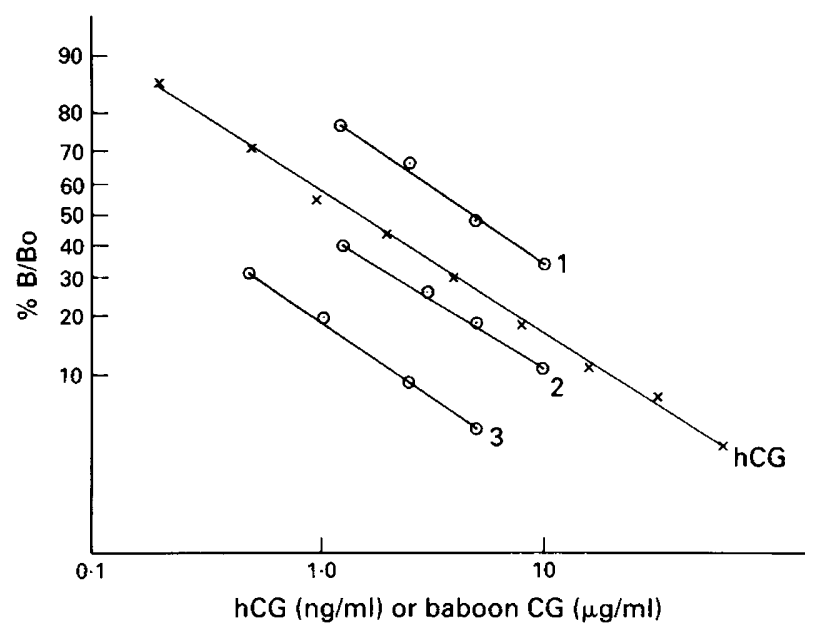

Fig. 1. Dose-response curves of hCG, baboon placental (1) and urinary (2) preparations at the Con A chromatography step. The urinary preparation purified by affinity chromatography is represented by 3 . 
Table 1. Potencies of baboon extracts during purification

\begin{tabular}{lcc}
\hline & Urine & Placenta \\
\hline Starting material & $26 \cdot 0$ & \\
Potency (i.u./mg) & $3400 \cdot 0$ & $0 \cdot 49$ \\
Weight (mg) & $88400 \cdot 0(81203 \cdot 0)^{*}$ & $10000 \cdot 0$ \\
Total activity (i.u.) & & $4900 \cdot 0(4818 \cdot 0)^{*}$ \\
DEAE 52 & $400 \cdot 0$ & \\
Potency (i.u./mg) & $196 \cdot 0$ & $87 \cdot 5$ \\
Weight (mg) & $78400 \cdot 0(72800 \cdot 0)^{*}$ & $38 \cdot 67$ \\
Total activity (i.u.) & & $3382 \cdot 2(2963 \cdot 7)^{*}$ \\
Gl00 & $1400 \cdot 0$ & $175 \cdot 3$ \\
Potency (i.u./mg) & $51 \cdot 2$ & $17 \cdot 6$ \\
Weight (mg) & $71680 \cdot 0(62066 \cdot 7)^{*}$ & $30860 \cdot 0(2959 \cdot 8)^{*}$ \\
Total activity (i.u.) & & \\
Con A & $3185 \cdot 5$ & $585 \cdot 9$ \\
Potency (i.u./mg) & $19 \cdot 3$ & $3 \cdot 7$ \\
Weight (mg) & $61480 \cdot 0(55332 \cdot 0)^{*}$ & $2168 \cdot 0(1952 \cdot 1)$ \\
Total activity (i.u.) & & \\
Affinity chromatography & $4363 \cdot 7$ & - \\
Potency (i.u./mg) & $12 \cdot 1$ & - \\
Weight (mg) & $52800 \cdot 8(49104 \cdot 9)^{*}$ & - \\
Total activity (i.u.) & & \\
\hline
\end{tabular}

*Radioreceptor assay potency.

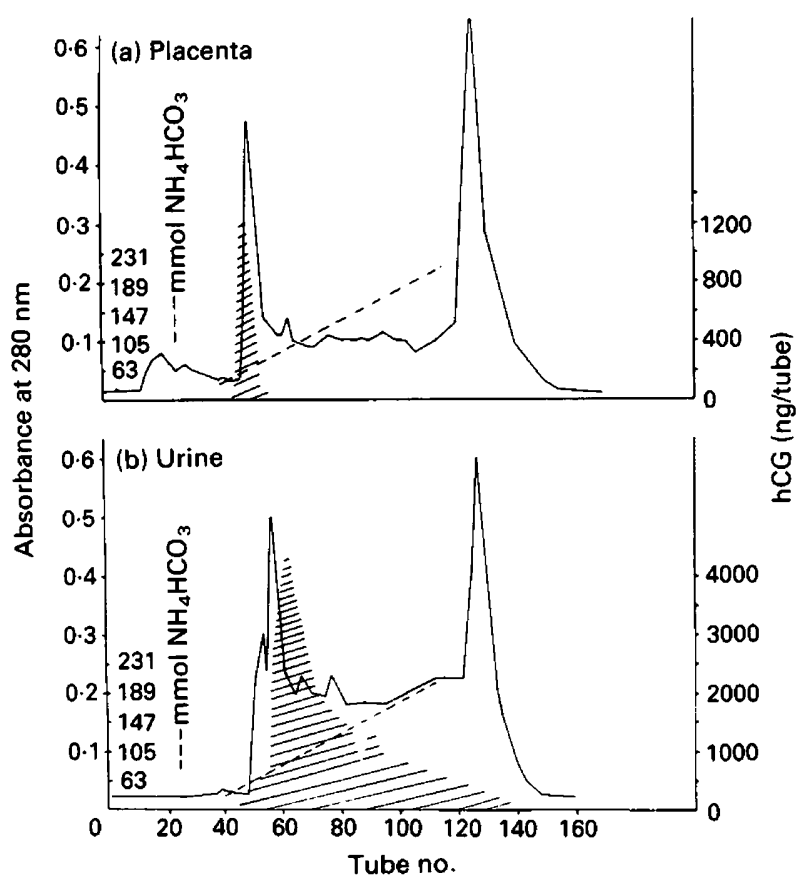

Fig. 2. DEAE-cellulose chromatography profiles for placental and urinary baboon CG. Column size was $2.6 \times 26 \mathrm{~cm}$, flow rate was $70 \mathrm{ml} / \mathrm{h}$ and $5-\mathrm{ml}$ fractions were collected. Shaded areas represent $\mathrm{CG}$ activity. 


\section{Chromatography on DEAE-cellulose}

Chromatography results obtained for the baboon urine and placental extracts are presented in Fig. 2 and Table 1. Results obtained for the comparative study are illustrated in Fig. 3. All four preparations (placental hCG and baboon CG; urinary hCG and baboon CG) eluted between 41 and $117 \mathrm{~mm}$-ammonium bicarbonate buffer. Both urine preparations showed a similar profile although urinary baboon CG appeared to have a slower moving component (Fig. 3). Similarly, both placental preparations had a similar chromatography pattern. The ratio of biological activity to immunological activity (B/I ratio) varied between 0.83 to 0.94 among the four preparations. Similar elution profiles were obtained when the baboon urinary and placental acetone extracts were run in two separate runs. The active material recovered from the ionic exchange column was $88 \cdot 7 \%$ for urinary and $96.0 \%$ for placental extracts. Corresponding increases in potency were $15-$ and 178-fold.

(d)

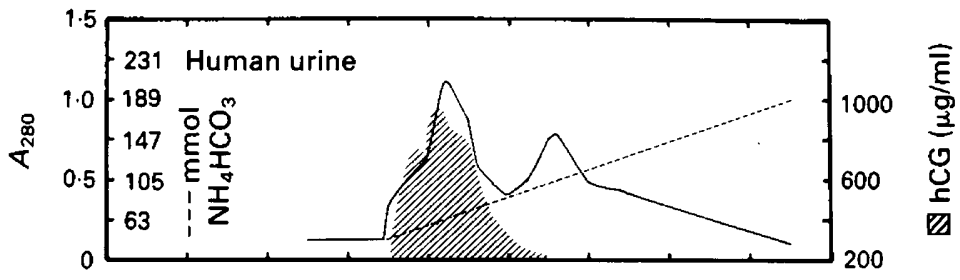

(c)

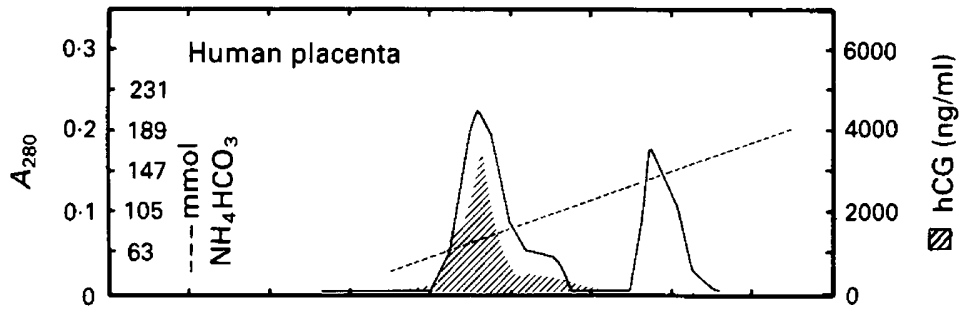

(b)

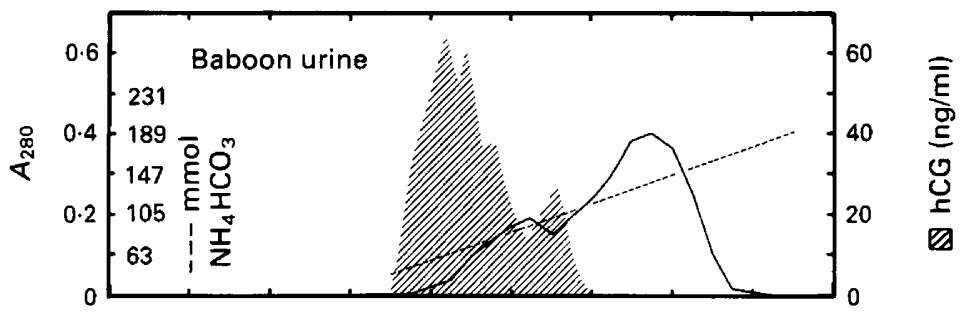

(a)

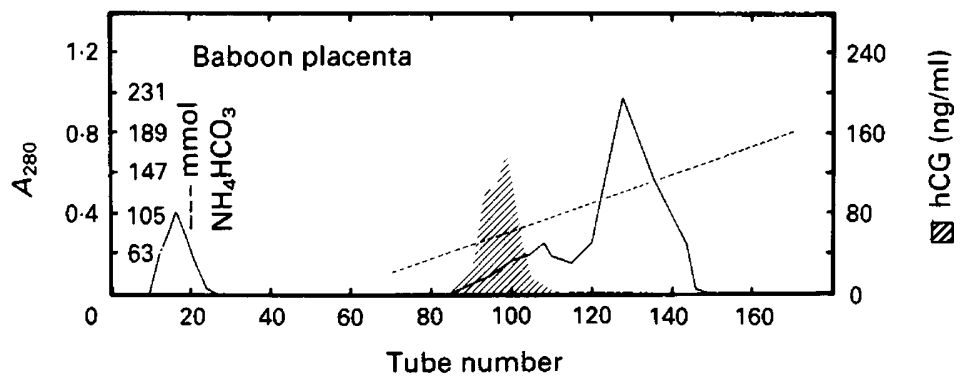

Fig. 3. DEAE-cellulose chromatography profiles for placental baboon (CG (a), urinary baboon CG (b), placental hCG (c) and urinary hCG (d). Column size was $2.6 \times 26 \mathrm{~cm}$, flow rate was $70 \mathrm{ml} / \mathrm{h}$ and $5-\mathrm{ml}$ fractions were collected. Note that the potency scales in the four panels are different. Shaded areas represent CG activity. 
Gel filtration on $G 100$

Gel filtration results for the baboon preparations are presented in Fig. 4 and Table 1. Urinary and placental extracts of baboon CG from the ionic exchange step eluted very near the elution position of radioiodinated urinary hCG, eluting before bovine serum albumin. The B:I ratios were 0.87 and 0.95 for the urinary and placental preparations respectively. When compared to the ionic exchange step, the active material recovered at this stage was $91 \%$ for urinary and $90 \%$ for placental baboon CG. Comparable potency increases were $3 \cdot 5$ - and $2 \cdot 0$-fold respectively.

When the gel filtration data were plotted in relation to the Stokes' radius, it was apparent that the two urinary and the two placental preparations had identical sizes with respect to one another.

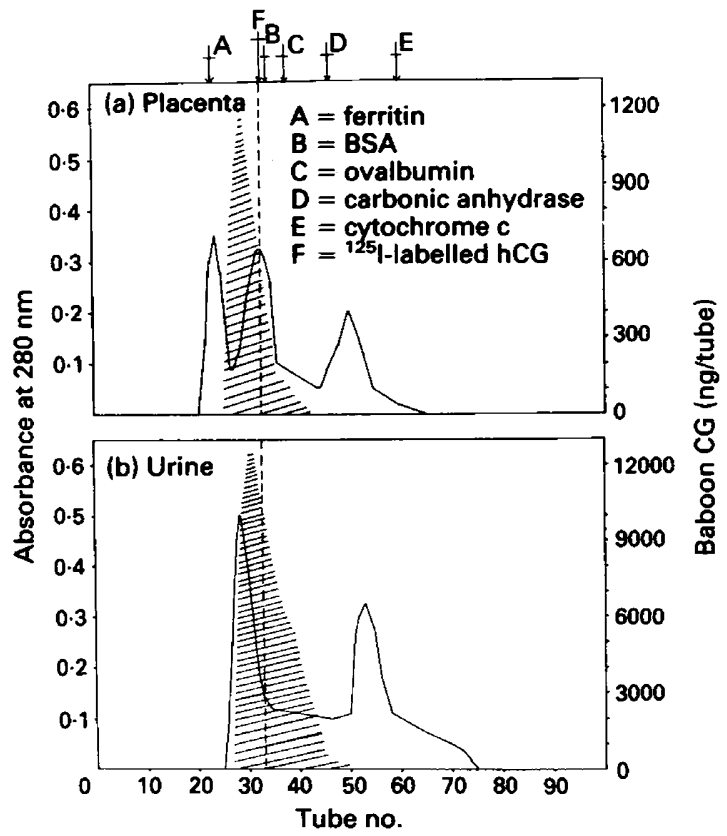

Fig. 4. Gel filtration profiles for placental and urinary baboon CG. Column size was $2.6 \times 82 \mathrm{~cm}$, flow rate was $20 \mathrm{ml} / \mathrm{h}$ and $5-\mathrm{ml}$ fractions were collected. Shaded areas represent CG activity.

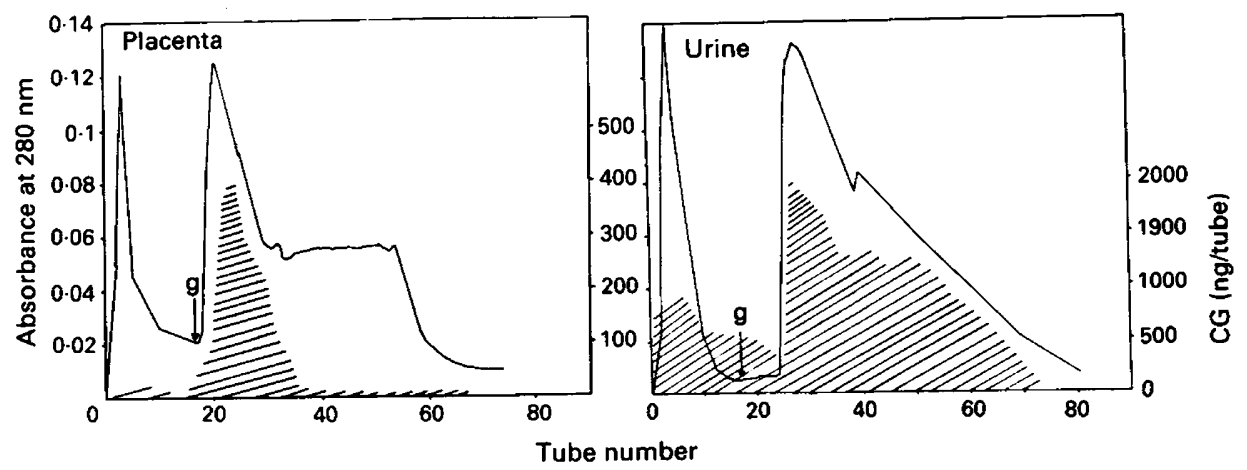

Fig. 5. Con A chromatography profiles for placental and urinary baboon CG. The position of application of the mannose gradient is shown by $\mathrm{g}$. Shaded areas represent CG activity. 


\section{Concanavalin A chromatography}

In all four preparations (Fig. 5; Table 1) activity was confined to the fraction which eluted with

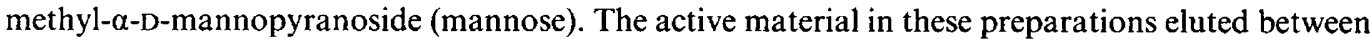
120 and $480 \mathrm{~mm}$-mannose. The B:I ratios for all preparations were between 0.90 and 0.96 . Total recovery of active fractions at this stage was $85 \%$ and $70 \%$ for urinary and placental baboon CG respectively when compared with the gel filtration step. The corresponding increases in potency were $2 \cdot 2-$ and $3 \cdot 3$-fold.

\section{Affinity chromatography}

Most of the active material in the Con A urinary baboon CG preparation came off the column with $1 \mathrm{M}$-propionic acid-10\% dioxane and had a potency of $4363.7 \mathrm{i} . \mathrm{u} . / \mathrm{mg}$ (Table 1). Only $12.1 \mathrm{mg}$ were recovered at this stage, and $1 \mathrm{mg}$ was recovered with the acetic acid/guanidine/glycine buffer. The activity of this material was only $190 \mathrm{i} . \mathrm{u} . / \mathrm{mg}$. A total purification of 167 -fold over the starting material was achieved and the total loss of active material was $40 \%$.

\section{Separation of subunits}

The elution pattern of $10 \mathrm{mg}$ urinary baboon $\mathrm{CG}$ at the affinity chromatography stage in an ion exchange column is shown in Fig. 6. Rechromatography of each peak on the Sephadex G100 column gave a single peak. Assays specific to the two baboon CG units were not available and in an hCG- $\beta$ RIA no activity could be measured in the first emergent peak whilst the second emergent peak had an activity greater than $1000 \mathrm{i}$.u. On this basis the peaks were designated as $\alpha$ and $\beta$ subunits. The Stokes' radii were $36.5,29.0$ and $22.0 \times 10^{-10} \mathrm{~m}$ for baboon CG and the $\beta$ - and $\alpha$-units respectively.

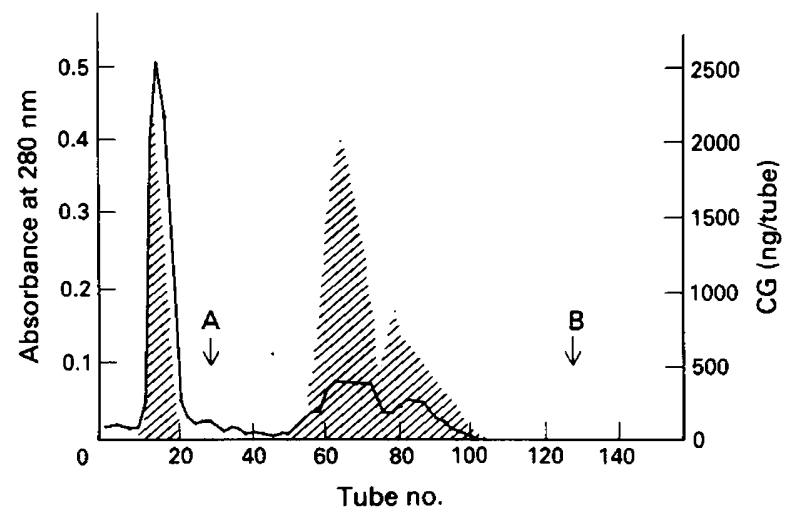

Fig. 6. Separation of the subunits of baboon CG on DEAE-52 cellulose. Positions A and B mark the application of $0-0 \cdot 1 \mathrm{M}$ - and $0 \cdot 1-0.5 \mathrm{M}$-sodium chloride in a buffer containing $3 \mathrm{~mm}$-boric acid, $8 \mathrm{~mm}$-disodium hydrogen phosphate and $3 \mathrm{~m}$-urea. Column size was $1.6 \times 20 \mathrm{~cm}$, flow rate was $45 \mathrm{ml} / \mathrm{h}$ and $5-\mathrm{ml}$ fractions were collected. Shaded area indicates CG activity.

\section{Isoelectric focussing}

Purified urinary baboon CG focussed in 5 bands between $\mathrm{pH} 4.2$ and 5.5 when the pH was measured by an LKB surface electrode (Fig. 7). The gel between these pH points contained immunoactive baboon CG. Of the total activity of $500 \mathrm{i} . u$. applied to the gel, $428 \mathrm{i} . \mathrm{u}$. were recovered in the $\mathrm{pH}$ range of $4 \cdot 2$ to $5 \cdot 5$. 


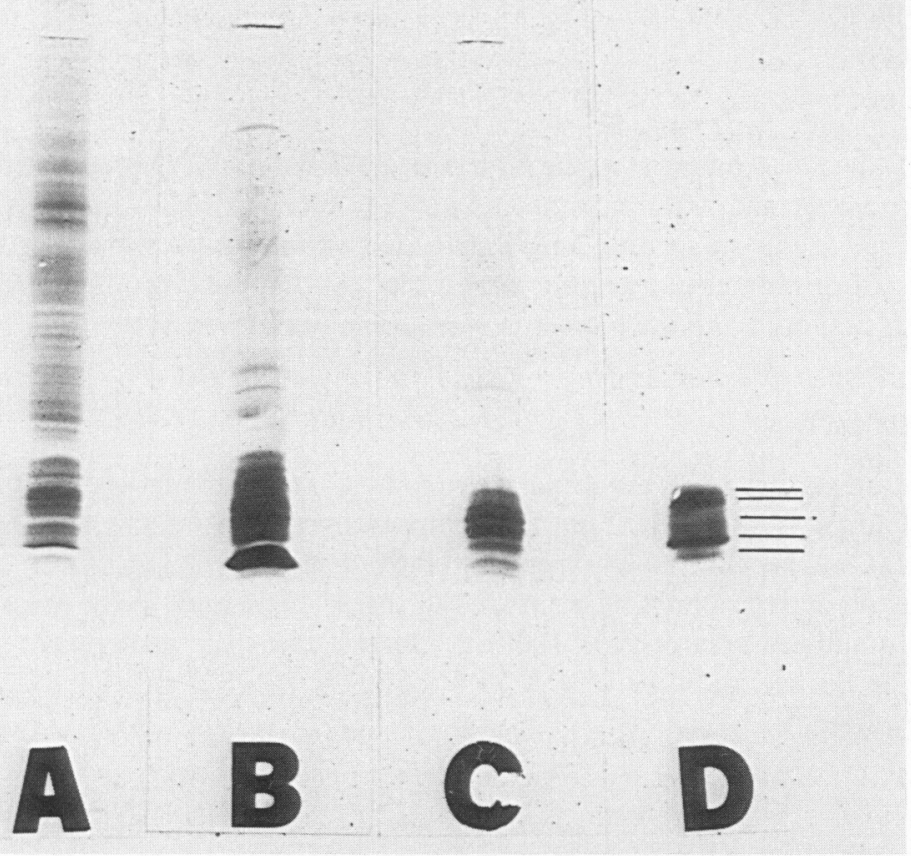

Fig. 7. Isoelectric focussing pattern of urinary baboon CG preparations: crude (A), ionic exchange step (B), gel filtration (C) and affinity purified (D). The five bands visible with the purified preparation are indicated by lines.

\section{Discussion}

Purification procedures for hCG (especially the urinary form) are well established (for example see Van Hell et al., 1968; Bahl, 1969; Mori, 1970; Canfield et al., 1971). However, this is not true for baboon CG. Chorionic gonadotrophin levels in the baboon fall rapidly after 35 days of gestation and the general circulatory levels are very low when compared with the human female (Stevens, 1980) and this may have accounted for the slow progress in establishing methods for its purification.

A pre-requisite for the extraction of baboon CG was a method for specifically distinguishing this material from the other proteins. The method of preference for monitoring the baboon CG component would be a specific radioimmunoassay against this molecule. The data presented in this paper clearly demonstrate that the placental and urinary extracts of the baboon CG show parallel dose-responses to the hCG standard curve when used in conjunction with the baboon CG antiserum produced in rabbits. Furthermore, it was apparent that the potency estimates obtained with the radioimmunoassay are in close agreement with those estimated by the radioreceptor assay. 
Ionic exchange chromatography studies suggested that urinary and placental hCG or baboon CG exhibit very similar behaviour in that all four preparations eluted in the same general concentration of ammonium bicarbonate. However, urinary baboon CG appeared to contain a more slowly migrating component with a heavier charge. The two placental preparations were slightly retarded and this suggests that these two preparations may have a higher negative charge when compared with the urinary hormone. Two reasons may account for this difference. The placental hormone is released into the maternal circulation and loses some of its sialic acid before its clearance and this gives it a slightly lower negative charge. Alternatively it is possible that the placental gonadotrophins contain more sialic acid. It is apparent that the net losses of active material at this stage were not high and that some purification of the hormones was achieved.

As in ionic exchange chromatography, baboon and human CG behaved in an identical manner in that they eluted at a similar time in gel filtration. Molecular weights cannot be calculated by gel filtration as this method is a measure of molecular dimensions and is known to give falsely high values for glycoproteins which have an appreciable carbohydrate content (Andrews, 1970). Nonetheless, it is apparent that the Stokes' radius for the two placental preparations and the two urinary preparations is similar. This suggests that the two urinary hormones are slightly larger than the placental ones. This could simply be due to the presence of more carbohydrate moieties in the urinary molecules, or more likely to them being unfolded, giving them an apparent increase in molecular dimensions. At this stage of purification, losses of active material were again negligible and a net increase in potency was achieved.

Gonadotrophin activity bound to Con $\mathrm{A}$ which has been shown to bind glycoproteins (Clarke \& Denborough, 1971). This suggests that baboon CG, like hCG, is a glycoprotein. It is established that, for binding interactions with Con A, polysaccharides need to have C-3, C-4 and C-5 hydroxyl groups available for binding (Goldstein et al., 1965). Placental baboon CG appeared to bind to Con A more strongly than did placental hCG or urinary baboon CG in that it was eluted from the

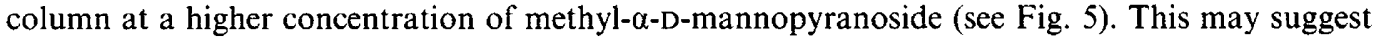
that placental baboon CG may have either a higher concentration of mannose or that more of the C-3, C-4 and C-5 hydroxyl groups are exposed in this preparation. Once again, net losses were negligible and significant increases in potency were achieved.

Purified hCG has been reported to give up to 6 bands on isoelectric focussing (Brossmer et al., 1971; Merz et al., 1974; Qazi et al., 1974) and this molecule also exhibits microheterogeneity in terms of its behaviour in ionic exchange chromatography and polyacrylamide gel electrophoresis (Goverde et al., 1968; Van Hell et al., 1968; Bahl, 1969; Graesslin et al., 1973; Merz et al., 1974). All these forms of hCG have been shown to have an almost identical amino acid composition with variation in their carbohydrate composition, especially the sialic acid content (Bahl, 1973) and it has been suggested that this microheterogeneity could come from the introduction of artefacts during isolation or from incomplete synthesis of carbohydrate chains. Purified baboon CG gave 5 bands upon isoelectric focussing and this, taken together with the ionic exchange chromatography results, suggests that this molecule, like hCG, displays microheterogeneity.

The Stokes' radii values for the native $\left(35 \times 10^{-10} \mathrm{~m}\right), \alpha$-subunit $\left(22 \times 10^{-10} \mathrm{~m}\right)$ and $\beta$ subunit $\left(29 \times 10^{-10} \mathrm{~m}\right)$ of baboon CG compare well with those reported for hCG $(33 ;$ Mori, 1970), $\alpha$-hCG (23.3; Morgan \& Canfield, 1971) and $\beta$-hCG (30-2; Morgan \& Canfield, 1971).

We conclude that baboon CG and hCG are very similar with respect to their physicochemical properties. Both molecules display similar behaviour during ionic exchange chromatography and isoelectric focussing. They have similar Stokes' radii, both have two non-covalently linked subunits and display microheterogeneity. Baboon $\mathrm{CG}$ can be purified using the same methods that have been developed for hCG.

This investigation received financial support from the Special Programme of Research, Development, and Research Training in Human Reproduction, World Health Organization. 


\section{References}

Andrews, P. (1970) Estimation of molecular size and molecular weights of biological compounds by gel-filtration. In Methods of Biochemical Analysis, Vol. 18, pp. 1-93. Ed. D. Glick. Interscience, New York.

Bahl, O.P. (I969) Human chorionic gonadotrophin. I. Purification and physicochemical properties. J. biol. Chem. 244, 567-574

Bahl, O.P. (1973) Chemistry of human chorionic gonadotrophin. In Hormonal Proteins and Peptides, pp. 17I-199. Ed. C. H. Li. Academic Press, New York.

Bambra, C.S., Eley, R.M. \& Wall, H. (1984) Limitations of the non-human pregnancy kit for pregnancy diagnosis in baboons. J. med. Primatol. 13, 219-227.

Brossmer, R., Dornerm, M., Hilgenfeldt, U., Leidenberger, E. \& Trude, E. (1971) Purification and characterization of hCG. FEBS Letters 15, 33-37.

Canfield, R.E., Morgan, F.J., Kammerman, S., Bell, J.J. \& Agosto, G.M. (1971) Studies of human chorionic gonadotrophin. Recent Prog. Horm. Res. 27, 121-164.

Clarke, A.E. \& Denborough, M.A. (1971) The interaction of Concanavalin A with blood-group substance glycoproteins from human secretions. Biochem. J. 121, 811-816.

Goldstein, I.J., Holleman, C.E. \& Smith, E.E. (1965) Protein carbohydrate interaction of Concanvalin A with polysaccharides. Biochemistry, N.Y. 4, 876-883.

Goverde, B.C., Veenkamp, F.J.N. \& Homan, J.D.H. (1968) Studies on human chorionic gonadotrophin. Acta endocr., Copenh. 59, 105-119.

Graesslin, D., Weise, H.C. \& Braendle, W. (1973) The microheterogeneity of human chorionic gonadotrophin (hCG) reflected in the $\beta$-subunits. FEBS Letters 31, $214-217$.

Heap, R.B. \& Perry, J.S. (1974) The maternal recognition of pregnancy. Br. J. Hosp. Med. 12, 8-15.

Hearn, J.P. (1980) The immunobiology of chorionic gonadotrophin. In Immunological Aspects of Reproduction and Fertility Control, pp. 229-244. Ed. J. P. Hearn. MTP Press Ltd, Lancaster.

Keutmann, H.T., McIlroy, P.J., Bergert, E.R. \& Ryan, R.J. (1983) Chemically deglycosylated human chorionic gonadotrophin subunits. Characterization and biological properties. Biochemistry, N.Y. 22, 3067-3072.

Lee, C.Y. \& Ryan, R.J. (1975) Radioreceptor assay for human chorionic gonadotrophin. J. clin. Endocr. Metab. 40, 288-293.

Levy, D.E. \& Eveleigh, J.W. (1978) Reversed immunosorbents: a simple method for specific antibody immobilization. J. Immunol. Methods 22, 131-142.

Merz, W.E., Helgenfeldt, V., Dorner, M. \& Brossmer, R. (1974) Biological, immunological and physical investigation on human chorionic gonadotrophin. Hoppe-Seyler's Z. Physiol. Chem. 335, 1035-1041.
Morgan, W.E. \& Canfield, R.E. (1971) Nature of the subunits of human chorionic gonadotrophin. Endocrinology 88, 1045-1052.

Mori, K.F. (1970) Antigenic structure of human chorionic gonadotrophin: importance of protein moiety to the antigenic structure of human chorionic gonadotrophin. Endocrinology 86, 97-106.

Ochieng, J. (1982) Preliminary study of heterogenous forms of chorionic gonadotrophin $(b C G)$ in the placenta, serum and urine of pregnant baboons (Papio anubis). M.Sc. Thesis, Ohio State University.

Ottobre, J.S. \& Stouffer, R.L. (1984) Persistent versus transient stimulation of the macaque corpus luteum during prolonged exposure to hCG: a function of the age of the corpus luteum. Endocrinology 114, 2175-2182.

Qazi, H.M., Mukherjee, G., Javidi, K., Pala, A. \& Diczfalsuzy, E. (1974) Preparations of highly purified human chorionic gonadotrophin by isoelectricfocusing. $J$. Biochem. 47, 219-229.

Ryan, R.J. (1969) Stokes radius of human pituitary hormones and demonstration of dissociation of luteinizing hormone. Biochemistry, N.Y. 8, 495-500.

Short, R.V. (1969) Implantation and maternal recognition of pregnancy. In Foetal Autonomy, pp. 2-26. Eds G. E. W. Wolstenholme \& M. O'Connor. Churchill, London.

Snedecor, G.W. \& Cochran, W.G. (1980) Analysis of covariance. In Statistical Methods, pp. 365-392. Eds G. W. Snedecor \& W. G. Cochran. Iowa State University Press, Ames.

Stevens, V.C. (1980) Vaccines against pregnancy. In Recent Advances in Fertility Regulation, pp. 211-247. Eds C. C. Fen, D. Griffin \& A. Woolman. Atar, S.A., Geneva.

Talwar, G.P., Sharma, N.C., Duby, S.K., Salahuddin, M., Das, C., Ramakrishnan, S., Kumar, S. \& Hingorani, V. (1976) Iso-immunization against hCG with conjugates of processes $\beta$-subunits of the hormone and Tetanus toxoid. Proc. natn. Acad. Sci. U.S.A. 73, 218-222.

Tullner, W.W. (1974) Comparative aspects of primate chorionic gonadotrophins. Contrib. Primat. 3, 235-357.

Van Hell, H.R., Matthitsen, R.J. \& Homan, J.D.H. (1968) Studies on human chorionic gonadotrophin I. Purification and some physicochemical properties. Acta endocr., Copenh. 59, 89-104.

Winter, A., Ek, K. \& Anderson, U. (1977) Analytical electrofocusing in thin layers of polyacrylamide gels. LKB Application Note 250. 